\title{
TECNOLOGIA DE OBTENÇÃO DE ARGILA ORGANOFÍlICA VISANDO SUA UTILIZAÇÃO COMO ADSORVENTE PARA REMOÇÃO DE ÓLEO
}

\author{
E. L. SILVA ${ }^{1}$, L. A. LIMA ${ }^{1}$ e M. G. F. RODRIGUES ${ }^{1}$ \\ 1 - Universidade Federal de Campina Grande - Departamento de Engenharia Química \\ E-mail para contato: ellay_lop@hotmail.com
}

\begin{abstract}
RESUMO - Este trabalho estuda sobre a tecnologia de obtenção e caracterização de uma argila organofílica visando sua utilização como adsorvente para a remoção de compostos orgânicos de efluentes, sendo uma alternativa para a remediação ambiental. A argila utilizada foi a bentonita sódica natural (BSN-01), que foi modificada através da substituição dos cátions sódio $(\mathrm{Na}+)$ interlamelares estruturais, por cátions quaternários do sal cloreto de cetil trimetil amônio. As técnicas utilizadas para caracterização das amostras da argila foram: Capacidade de troca catiônica (CTC), Difração de raio X (DRX), Espectrofotometria de raios X por Energia Dispersiva (EDX) e Teste de Capacidade de adsorção. A composição química foi verificada através da análise de EDX. Os resultados de DRX evidenciaram a intercalação dos cátions quaternários de amônio do sal na estrutura da argila, confirmando a efetivação da organofilização. A argila modificada quimicamente mostrou capacidade de adsorção superior à argila natural.
\end{abstract}

\section{INTRODUÇÃO}

Nos últimos anos, considerável atenção tem sido dada ao controle da emissão de efluentes oleosos e seu impacto ambiental (Srijaroonrat et al., 1999). Neste sentido, conforme Alther (2008), a modificação química de argilas com sais quaternários de amônio, através de troca catiônica, atualmente tem ganhado crescente importância na área ambiental.

Argilas são materiais terrosos, naturais, contendo silicatos hidratados de alumínio, ferro e magnésio; constituídos de minerais finamente divididos (argilominerais), podendo conter particulas de quartzo, calcita, pirita, entre outros minerais, matéria orgânica e sais solúveis. Possuem alta capacidade de troca catiônica, baixo custo, elevado grau de expansão em suspensão aquosa e estrutura cristalina em camadas (filossilicatos), constituídos por folhas contínuas de tetraedros $\left(\mathrm{SiO}_{4}\right)$, ordenados de forma hexagonal, condensados com folhas octaédricas de hidróxidos de metais di e trivalentes; os argilominerais são essencialmente constituídos por partículas (cristais) de pequenas dimensões, geralmente abaixo de 2mm (Souza Santos, 1992; Vossen, 2009). A superfície da argila natural é hidrofílica e essa característica a torna um adsorvente ineficaz na remoção de compostos orgânicos. Tal dificuldade tem sido superada pela introdução de moléculas de surfactante catiônico no espaço interlamelar da argila, tornando-a assim organofílica (Park et al., 2011). 
Os compostos orgânicos mais utilizados na preparação de argilas organofílicas são os sais quaternários de amônio de cadeias longas (Paiva et al., 2008). Apresentam um ou mais grupos de hidrocarbonetos de cadeia extensa ligados diretamente ao átomo de nitrogênio, constituem um grupo importante de produtos químicos industriais, que podem ser aplicados nas argilas sem agredir o meio ambiente, por serem compostos não tóxicos, biodegradáveis e com propriedades de tensoativos ou surfactantes (Silva e Ferreira, 2008). Os cátions quaternários, como $\mathrm{C}_{16}$ ou $\mathrm{C}_{18}$, permitem a formação de grandes galerias com maiores diâmetros entre as camadas 2:1 com propriedades hidrofóbicas, ou seja, com aumento do comprimento, isto é, do número de carbonos da molécula linear alquílica é possível conseguir que o cátion quaternário de amônio fique perpendicular ao plano das camadas 2:1 entre as quais está intercalado, provocando com isso um maior inchamento da distância interplanar das argilas (Barbosa et al., 2010).

A preferência quanto ao uso de esmectitas nessas sínteses deve-se às pequenas dimensões dos cristais e à elevada CTC (capacidade de troca de cátions) desses argilominerais, e isso faz com que as reações de intercalação sejam mais rápidas (Pereira, 2003).

A crescente necessidade de eficientes processos de separação óleo/água, por exemplo, gerada principalmente pelas legislações ambientais cada vez mais rígidas, tem voltado grande atenção para uso de argilas organofílicas no processo de tratamento de efluentes oleosos, sendo esta uma alternativa bastante eficiente antes de sua disposição ao meio ambiente.

É neste sentido que este trabalho tem como objetivo utilizar a tecnologia de obtenção e caracterização de uma argila organofílica visando sua utilização como adsorvente para a remoção de poluentes orgânicos de efluentes.

\section{MATERIAIS E MÉTODOS}

A argila bentonita sódica natural (BSN-01) utilizada foi fornecida pela empresa Bentonisa, localizada no estado da Paraíba - Brasil. O sal quaternário utilizado foi o cloreto de cetil trimetil amônio (Genamin) adquirido através da empresa Clariant.

\subsection{Obtenção da argila Organofílica}

Preparou-se uma dispersão aquosa, sob agitação mecânica, adicionando-se $32 \mathrm{~g}$ da argila aos poucos a um becker contendo $768 \mathrm{ml}$ de água destilada, em agitação por 20 minutos. Visto que a argila é monocatiônica, não houve a necessidade de realizar a etapa do tratamento com o carbonato de sódico. Em seguida, acrescentou-se o sal quaternário cloreto de cetil trimetil amônio, na proporção de 100 meq/100g de argila e continuou-se a agitação por $30 \mathrm{~min}$. Então, realizou-se o processo de filtração à vácuo. O filtrado obtido foi seco em estufa a $60{ }^{\circ} \mathrm{C}$ durante $24 \mathrm{~h}$, sendo em seguida desagregado, triturado, passado em peneira malha 200 mesh e submetido à caracterização. As etapas do processo de organofilização são estabelecidos conforme mostra a Figura1. 


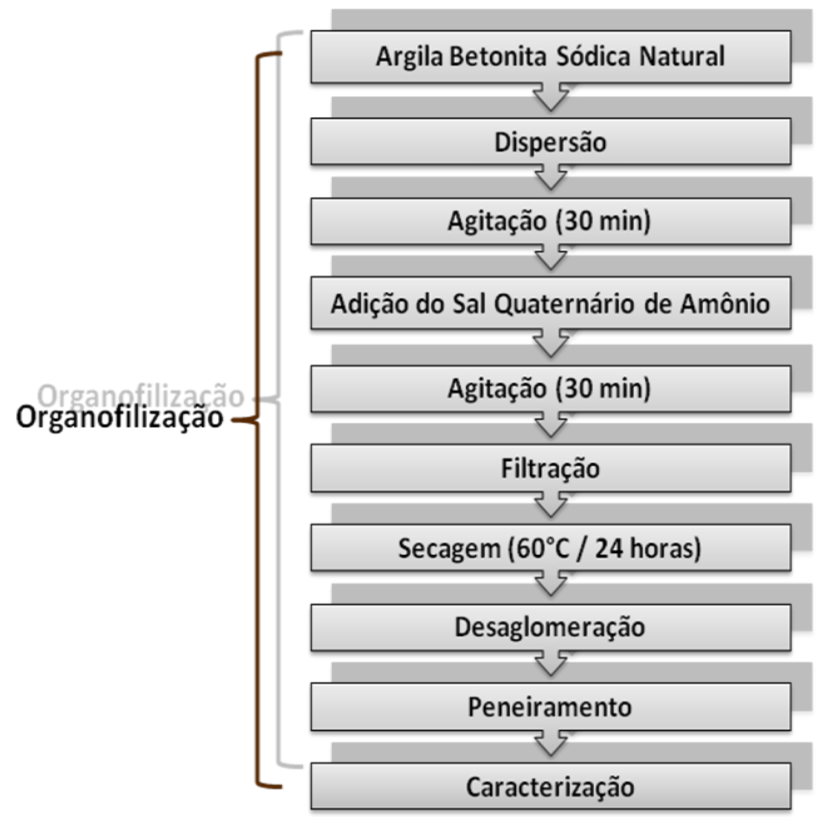

Figura1- Esquema das etapas de obtenção da argila BSN 01 organofílica.

\subsection{Caracterizações}

Capacidade de troca catiônica (CTC): Permite identificar e quantificar a composição química global de um sólido em pó. A análise foi efetuada quantitativamente, utilizando-se o equipamento Espectrofotômetro de Raios X - Shimadzu (modelo 720).

Difração de raios $X(\mathrm{DRX})$ : As amostras foram analisadas utilizando o método do pó empregando-se um difratômetro Shimadzu XRD-6000 com radiação $\mathrm{CuK} \alpha$, tensão de $40 \mathrm{KV}$, corrente de $30 \mathrm{~mA}$, tamanho do passo de 0,020 $2 \theta$ e tempo por passo de 1,000s, com velocidade de varredura de $2^{\circ}(2 \theta) / \mathrm{min}$, com ângulo $2 \theta$ percorrido de $0^{\circ}$ a $50^{\circ}$.

Espectrofotometria de Raios X por Energia Dispersiva (EDX): Permite identificar e quantificar a composição química global de um sólido em pó. A análise foi efetuada utilizando-se um Espectrofotômetro de Raios X - Shimadzu (modelo 720).

\subsection{Teste de Capacidade de Adsorção}

A avaliação da capacidade de adsorção nos solventes orgânicos gasolina, querosene e óleo diesel, foi baseado "Standard Methods of Testing Sorbent Performance of Adsorbents" através das normas ASTM F716-82 e ASTM F726-99. Em um recipiente Pyrex colocou-se o solvente a ser testado até uma altura de $2 \mathrm{~cm}$. Em uma cesta (fabricada de tela de Aço Inoxidável com malha ABNT 200 , abertura de $0,075 \mathrm{~mm}$ ) colocou-se $1,00 \mathrm{~g}$ do material adsorvente a ser testado. Esse conjunto foi pesado e colocado no recipiente com o solvente, onde permaneceu por 15 minutos. Após esse tempo, deixou-se escorrer o excesso por 15 segundos e realizou-se uma nova pesagem. O resultado é dado em gramas do solvente por gramas do adsorvente. 


\section{RESULTADOS E DISCUSSÃO}

\subsection{Capacidade de Troca Catiônica (CTC)}

Segundo Souza Santos (1989) A determinação de CTC é muito útil para montmorilonitas e vermiculitas, para os demais grupos de argilominerais, isolados ou de mistura com minerias inertes não tem valores elucidativos apreciáveis porque não permite identificar univocamente o tipo de material presente. Os valores de CTC de argilas esmectitas relatados na literatura (Souza Santos (1992)), encontram-se na faixa de 3 a 150 meq/100g. Pereira (2007) afirma que esses valores altos de capacidade de troca catiônica, indicam que a argila apresenta uma baixa quantidade de impurezas ou um alto nível de substituições isomórficas. Através do método do acetato de amônio realizado em equipamento de Kjeldahl, obteve-se o resultado de 85 meq/100g para argila BSN-01 natural, valor esse dentro da faixa esperada para argilas do tipo esmectita.Na Tabela 1 está apresentado o resultado referente à capacidade de troca catiônica (CTC) para a argila BSN-01 natural.

Tabela 1 - Capacidade de Troca catiônica da argila BSN-01.

\begin{tabular}{|c|c|}
\hline Argila natural & CTC (meq/100g de argila) \\
\hline BSN-01 & 85 \\
\hline
\end{tabular}

\subsection{Difração de Raios X (DRX)}

$\mathrm{Na}$ Figura 2 são apresentados os difratogramas de raios $\mathrm{X}$ das amostras da argila BSN-01 natural e organofílica.

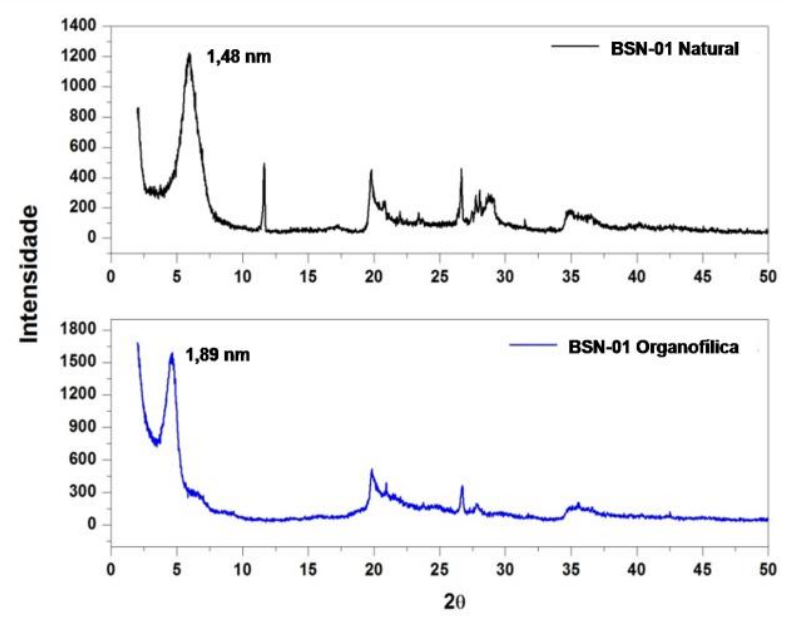

(a)

Figura 2- Difratogramas de Raios X das amostras: argila BSN-01 natural (a) e argila BSN-01 organofílica (b).

Por meio dos difratogramas é possível verificar que a argila BSN-01 natural (Figura 2a) apresenta reflexão do grupo da esmectita (E) que aparece em aproximadamente $6,63^{\circ}$ e corresponde ao espaçamento basal $\left(\mathrm{d}_{001}\right)$ de $14,88 \AA(1,48 \mathrm{~nm})$. Observam-se também outros picos que são 


\section{9 a 22 de outubro de 2014 \\ Florianópolis/SC}

referentes a minerais não esmectíticos como o quartzo que se apresenta como impureza (Wang et al., 2004 e Xi et al., 2010). É possível verificar, a partir da Figura 2, que a argila natural evidencia a intensidade mais alta dos picos característicos da argila do tipo esmectíticos e se encontram dentro da faixa apresentada pelos argilominerais desse grupo 1,2 - 1,4 nm (Murray, 2006).

$\mathrm{Na}$ Figura 2b (argila organofílica), é possível observar um deslocamento de picos e um aumento do espaçamento basal de $14,88 \AA$ para $18,93 \AA$ ( $1,48 \mathrm{~nm}$ para $1,89 \mathrm{~nm})$, ao comparar com a Figura 2a (argila natural). Esta diferença foi de 4,05 $\AA$ (0,41 nm). Esse aumento expressivo na $\mathrm{d}_{(001)}$ da argila BSN-01 organofílica, confirma a efetiva intercalação do cátion quaternário de amônio (Genamin) nas camadas interlamelares da argila. Essa expansão da camada da argila também foi encontrada na literatura independentemente do sal utilizado (Silva et al., 2007 e Rodrigues et al., 2010). Verifica-se ainda que a perda da organização perceptível ao se comparar a Figura 2a com a Figura 2 b ocorre em função da saída de cátions trocáveis e entrada de um ligante com maior caráter covalente como o sal quaternário de amônio, na estrututa da argila.

\subsection{Espectrofotometria de raios X por Energia Dispersiva (EDX)}

Na Tabela 2 estão apresentados os resultados das composições químicas das amostras (argila BSN-01 natural e organofílica), na forma de óxidos.

Tabela 2- Composição química das amostras (argila BSN-01 natural e organofílica).

\begin{tabular}{|c|c|c|}
\hline Composição Química & BSN-01 natural (\%) & BSN-01 organofílica (\%) \\
\hline $\mathrm{SiO}_{2}$ & 59,03 & 60,47 \\
\hline $\mathrm{Al}_{2} \mathrm{O}_{3}$ & 28,41 & 29,05 \\
\hline $\mathrm{MgO}$ & 3,17 & 3,17 \\
\hline $\mathrm{Fe}_{2} \mathrm{O}_{3}$ & 6,59 & 6,96 \\
\hline $\mathrm{CaO}$ & 1,16 & 0,28 \\
\hline $\mathrm{Na}_{2} \mathrm{O}$ & 1,64 & 0,07 \\
\hline Total & \multicolumn{2}{|c|}{100} \\
\hline
\end{tabular}

As amostras da argila BSN-01, tanto na sua forma natural quanto modificada quimicamente (organofílica) apresentam uma maior quantidade de óxido de silício $\left(\mathrm{SiO}_{2}\right)$ e de óxido de alumínio $\left(\mathrm{Al}_{2} \mathrm{O}_{3}\right)$ se comparado com os outros componentes, totalizando um percentual acima de $80 \%$ e $89 \%$, respectivamente. Também apresentam um teor apreciável de óxido de ferro na forma de óxido de ferro III $\left(\mathrm{Fe}_{2} \mathrm{O}_{3}\right)$. O magnésio, o cálcio e o sódio, estão presentes na amostra, geralmente, como óxidos de cátions trocáveis. Após a organofilização, observou-se uma redução significativa do óxido de cálcio e principalmente do óxido de sódio, decorrente da troca catiônica que ocorre com a intercalação dos cátions de amônia na estrutura da argila. Óxidos com teores menores de $1 \%$, no 


\section{9 a 22 de outubro de 2014 \\ Florianópolis/SC}

geral, não influenciam significativamente as propriedades das argilas. (Menezes et al., 2009; Grim, 1968).

Pode-se verificar que: (i) $\mathrm{O}$ conteúdo de $\mathrm{SiO}_{2}$ é devido à sílica livre, que é proveniente do quartzo; (ii) $\mathrm{O} \mathrm{Al}_{2} \mathrm{O}_{3}$ existente está em sua maior parte combinado formando os argilominerais, geralmente caulinita; (iii) $\mathrm{O} \mathrm{Fe}_{2} \mathrm{O}_{3}$ presente nas amostras está possivelmente relacionado ao ferro presente na estrutura cristalina do argilomineral do grupo da esmectita (Souza Santos, 1992).

\subsection{Teste de capacidade de adsorção}

A superfície do argilomineral é hidrofílica e essa característica torna a argila natural um adsorvente ineficaz na remoção de compostos orgânicos (Park et al., 2011). A argila BSN-01 natural apresenta baixos valores de capacidade de adsorção, 1,07 para o solvente gasolina, 0,81 para o solvente óleo diesel e 0,95 para o solvente querosene, seguindo portanto a ordem: gasolina > querosene > óleo diesel. Esta baixa eficiência de adsorção da argila natural é superada pela introdução de moléculas do sal quaternário de amônio-Genamin, nos espaços interlamelares da mesma, tornando-a assim organofílica (Oliveira, 2012; Cunha, 2013; Araújo, 2013). Conforme os resultados apresentados na Figura 3, referentes aos testes de capacidade de adsorção que tem por finalidade avaliar o potencial das amostras: argila BSN-01 e argila BSN-01 organofílica como adsorventes em solventes orgânicos tais como gasolina, querosene e óleo diesel, utilizando a metodologia baseada nas normas ASTM F716-82 e ASTM F726-99:

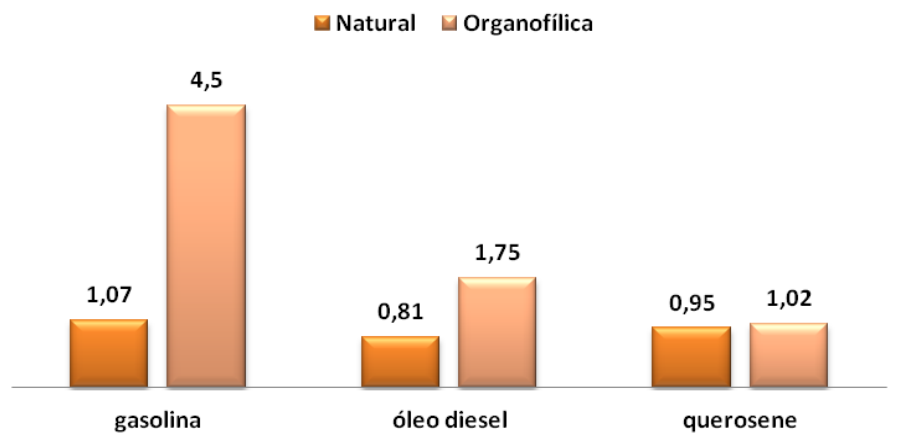

Figura 3- Capacidade de adsorção das amostras: argila BSN-01 natural e argila BSN 01 organofílica.

De acordo com os resultados expostos na Figura 3 é possível observar que a argila BSN-01 organofílica apresenta melhor adsorção dos compostos orgânicos, quando comparadas com sua forma natural. Este fato mostra que o processo de organofilização provocou mudanças nas propriedades químicas da argila, alterando suas propriedades para hidrofóbicas.

A argila BSN-01 organofílica apresentou um aumento significativo na quantidade de material adsorvido. Com relação ao solvente gasolina, a argila organofílica adsorveu 343\% a mais do que a argila natural. No caso do óleo diesel, houve um aumento de $94 \%$ na quantidade de material adsorvido pela argila. O solvente querosene foi o que apresentou o menor aumento da capacidade de adsorção após a organofilização, em torno de 7\%. Apresentando melhor resultado na seguinte ordem: gasolina > óleo diesel > querosene. A amostra BSN-01 organofílica mostrou melhor interação com o solvente gasolina. De acordo com Silva (2012) este fato pode ser explicado, levando-se em 


\section{9 a 22 de outubro de 2014 \\ Florianópolis/SC}

consideração que os resultados nos testes de adsorção podem estar relacionados com a viscosidade dos solventes, tendo em vista que a gasolina têm menor viscosidade, uma vez que os resultados de viscosidade são: diesel - $8 \mathrm{mPa}$.s (600rpm) e 3,5 mPa.s (300rpm); querosene - $2 \mathrm{mPa} . \mathrm{s}(600 \mathrm{rpm})$ e 1 mPa.s (300rpm); gasolina - $2 \mathrm{mPa} . \mathrm{s}$ (600rpm) e $1 \mathrm{mPa} . \mathrm{s}$ (300rpm). Essa interação também pode estar relacionada diretamente à composição e estrutura química dos compostos orgânicos (Silva et al., 2011). Os resultados da capacidade de adsorção estão apresentados em gramas de solvente adsorvido por grama de argila.

\section{CONCLUSÕES}

A argila BSN-01 natural é uma argila pertencente ao grupo das esmectitas, fato confirmado pela difração de Raios X e pelos resultados da análise química (EDX). Os resultados das análises de DRX e EDX comprovaram ainda que a argila BSN-01 natural, além de possuir a esmectita como argilomineral predominante, ainda possui outras misturas dos minerais caulinita e quartzo. Obteve-se o resultado de $85 \mathrm{meq} / 100 \mathrm{~g}$ de capacidade de troca catiônica para argila BSN-01 natural, valor dentro da faixa esperada para argilas do tipo esmectita. Os resultados do teste de Capacidade de Adsorção confirmaram que após o processo de organofilização, a amostra apresentou capacidade de adsorção maior em relação à argila natural.

\section{REFERÊNCIAS}

ALTHER, G.R., Cleaning wastewater: Removing oil from water wich organoclays, Filtration Separation, v.45, p. 22-24, 2008.

ARAÚJO, I. N., Modificação química da argila BSN 02 com surfactante Genamin para uso na remoção de óleo em sistema de banho finito. Dissertação de mestrado, Universidade Federal de Campina Grande- PB, 74 f, 2013.

BARBOSA, R; SOUZA, D. D; ARAÚJO, E. M, MELO, T. J. A. Avaliação da estabilidade térmica de sais quaternários de amônio para uso em argilas organofílicas nacionais - Parte I. Cerâmica, v. 56, p. 376-380, 2010.

CUNHA, R. S. S., Obtenção de argila organofílica visando o processo de descontaminação de águas oleosas. Dissertação de mestrado, Universidade Federal de Campina Grande- PB, 102 f, 2013.

GRIM, R. E.; Clay Mineralogy, 2nd Ed., McGraw-Hill Book, New York, EUA, 1968.

MENEZES, R. R.; SOUTO, P. M.; SANTANA, L. N. L.; NEVES, G. A.; KIMINAMI, R. H. G. A.;FERREIRA, H. C. Argilas bentoníticas de Cubati, Paraíba, Brasil: Caracterização físicamineralógica.Cerâmica. 55: 163-169 (2009).

MURRAY, H. H.; Applied Clay Mineralogy. Developments in Clay Science, $1^{\text {a }}$ Ed., 2006.

OLIVEIRA, G. C.; Utilização de adsorventes (carvão ativado e argilas organofílicas) no processo de separação de emulsões óleo/água. Dissertação de Mestrado, Universidade Federal de Campina Grande- PB, 83 f, 2012. 
PAIVA, L. B.; MORALES, A. R.; VALENZUELA DÍAZ, F. R., Organoclays: properties, preparation and applications, Appl. Clay Sci. v.42, p.8-24, 2008.

PARK, Y.; AYOKO, G. A.; KRISTOF, J. A thermoanalytical assessment of an organoclay. J Therm Anal Calorim. v. 104, p.1-6, 2011.

PEREIRA, K. R. O. Ativação ácida e preparação de argilas organofílicas partindo-se e argila esmectítica proveniente do Estado da Paraíba. Dissertação de Mestrado. Programa de Pós-Graduação em Engenharia Química. Universidade Federal de Campina Grande, 2003.

PEREIRA, K. R. O.; RODRIGUES, M. G. F.; VALENZUELA-DIAZ, F. R. Síntese e caracterização de argilas organofílicas: comparação no uso de dois métodos. Revista Eletrônica de Materiais $e$ Processos, v.2, p.1-8, 2007.

RODRIGUES, S. C. G.; RODRIGUES, M. G. F.; PEREIRA, K. R. O.; VALENZUELA-DÍAZ, F. R. Performance or organophilic Clay as adsorbent in the oil/water separation process. Brazilian $J$. Petroleum and Gas 4:49-58, 2010.

SILVA, M.M.; RODRIGUES, M.G.F. Síntese de argilas organofílicas visando seu uso no tratamento de efluentes oleosos. Encontro Norte, Nordeste e Centro-Oeste de Catálise-IX Encat, 2012.

SILVA A, R. V.; FERREIRA H. C. Argilas bentoníticas: conceitos, estruturas, propriedades, usos industriais, reservas, produção e produtores/fornecedores nacionais e internacionais. Revista Eletrônica de Materiais e Processos, v.3.2, p.26-35, 2008.

SILVA, A.; VALENZUELA-DIAZ, F.R.; MARTINS, G. S. V.; RODRIGUES, M. G. F. Preparação de argilas organofilicas usando diferentes concentrações de sal quaternário de amônia. Cerâmica, v.53, p.417-422, 2007.

SIlVA, M. M.; PATRÍCIO, A. C. L.; LIMA, W. S.; LABORDE, H. M.; RODRIGUES, M. G. F. Preparação e avaliação da argila verde organofílica usando diferentes concentrações de surfactante catiônico visando seu uso na separação óleo/água. Scientia Plena, vol. 7, n. 9. p.171-180, 2011.

SOUZA SANTOS, P. Ciência e Tecnologia de Argilas, v. 1, 2a Ed., Ed. Edgard Blücher Ltda, 1989.

SOUZA SANTOS, P. Ciência e Tecnologia de Argilas. 2a Ed; São Paulo: Edgard Blücher. v. 2, 1992.

SRIJAROONRAT, P., JULIEN, E., AURELLE, Y., 1999, "Unstable secondary oil/water emulsion treatment using ultrafiltration: fouling control by backflushing", J. Membrane Sci., v. 159, pp.11-20, 1999.

VOSSEN, C.A. Nanocompósitos de ABS/PA e Argilas Organofílicas. Dissertação de Mestrado, Escola Politécnica, Universidade de São Paulo, São Paulo, SP. 2009.

WANG, C. C.; JUANG, L. C.; LEE, C. K.; HSU, T. C.; LEE, J. F.; CHAO, H. P. Effects of Exchanged Surfactant Cations on the Pore Structure and Adsorption Characteristics of Montmorillonite. J. Colloid Interface Sci., v.280, p.27-35, 2004.

XI Y.; MALLAVARAPU M.; NAIDU R. Preparation, characterization of surfactants modified Clay minerals and nitrate adsorption. Appl. Clay Sci., v.48, p. 92-96, 2010. 